\title{
Biogeographic origin and radiation of the Old World crocidurine shrews (Mammalia: Soricidae) inferred from mitochondrial and nuclear genes
}

\author{
Sylvain Dubey ${ }^{\mathrm{a}, \mathrm{b}, *}$, Nicolas Salamin ${ }^{\mathrm{b}}$, Manuel Ruedi ${ }^{\mathrm{c}}$, Patrick Barrière ${ }^{\mathrm{d}}$, Marc Colyn ${ }^{\mathrm{d}}$, Peter Vogel ${ }^{\mathrm{b}}$ \\ a School of Biological Sciences, University of Sydney, Sydney, NSW 2006, Australia \\ ${ }^{\mathrm{b}}$ Department of Ecology and Evolution, University of Lausanne, CH-1015 Lausanne, Switzerland \\ ${ }^{\mathrm{c}}$ Natural History Museum, P.O. Box 6434, 1211 Geneva 6, Switzerland \\ d Laboratoire Ecobio UMR 6553-CNRS, Université de Rennes 1, Station Biologique, F-35380 Paimpont, France
}

\section{A R T I C L E I N F O}

Article history:

Received 27 November 2007

Revised 24 June 2008

Accepted 2 July 2008

Available online 10 July 2008

\section{Keywords:}

Africa

Dispersion

Eurasia

Phylogeny

Pleistocene

Pliocene

\begin{abstract}
A B S T R A C T
The crocidurine shrews include the most speciose genus of mammals, Crocidura. The origin and evolution of their radiation is, however, poorly understood because of very scant fossil records and a rather conservative external morphology between species. Here, we use an alignment of 3560 base pairs of mitochondrial and nuclear DNA to generate a phylogenetic hypothesis for the evolution of Old World shrews of the subfamily Crocidurinae. These molecular data confirm the monophyly of the speciose African and Eurasian Crocidura, which also includes the fossorial, monotypic genus Diplomesodon. The phylogenetic reconstructions give further credit to a paraphyletic position of Suncus shrews, which are placed into at least two independent clades (one in Africa and sister to Sylvisorex and one in Eurasia), at the base of the Crocidura radiation. Therefore, we recommend restricting the genus Suncus to the Palaearctic and Oriental taxa, and to consider all the African Suncus as Sylvisorex. Using molecular dating and biogeographic reconstruction analyses, we suggest a Palaearctic-Oriental origin for Crocidura dating back to the Upper Miocene (6.8 million years ago) and several subsequent colonisations of the Afrotropical region by independent lineages of Crocidura.
\end{abstract}

(c) 2008 Elsevier Inc. All rights reserved.

\section{Introduction}

During most of the Tertiary Period, the African and Eurasian continental plates were isolated from each other by the Tethys Sea (Rögl, 1998). It was only during the Lower Miocene, about 18 million years (Myr) ago, that both continents were first connected by the closure of the Eastern Mediterranean seaway, i.e. the Gomphotherium land bridge (Rögl, 1998; Harzhauser et al., 2002). A land connection existed in the northwest (i.e. at the location of the actual Gibraltar Strait) 16-14 Myr ago during the Bethic crisis, and again during the Miocene-Pliocene transition via extensive land bridges during the Messinian salinity crisis, 5.6-5.3 Myr ago (Krijgsman et al., 1999).

Paleontological data revealed that major terrestrial faunal exchanges between the African and Eurasian continents took place during these periods of connections (Azzaroli and Guazzone, 1979; Thomas et al., 1982; Chevret, 1994). In addition to these geological events, climatic variations also played a crucial role in faunal diversification of Old World biotas. From the Late Eocene (40 Myr ago) up to now, warm and wet periods have intersected

\footnotetext{
* Corresponding author. Address: School of Biological Sciences, University of Sydney, Sydney, NSW 2006, Australia. Fax: +61 293515609.

E-mail address: sylvain.dubey@bio.usyd.edu.au (S. Dubey).
}

cold and dry ones, leading to deep faunal and floral turnovers. These climatic fluctuations led to major changes in habitat, e.g. the emergence of grassland savannah and open woodland in Africa during cold periods. As a consequence, the diversification of aridadapted fauna was facilitated (De Menocal, 2004), as well as the colonization of Africa by Eurasian-born species adapted to these habitats (Fu, 1998; Caujapé-Castells and Jansen, 2003; De Menocal, 2004; Amer and Kumazawa, 2005).

Usually, time estimates of faunal turnovers and diversifications based on paleontological data are available only for large mammals, due to a better preservation of large fossils compared to small ones over time (Alroy, 2003). This is indeed the case for small mammals such as shrews that left a scant fossil record. In such cases, molecular phylogenetic analyses coupled with recent advances in relaxed molecular clocks (Sanderson, 1997, 2002; Thorne and Kishino, 2002; Drummond et al., 2006) can help put estimated divergence times on nodes without fossils.

The Soricidae is one of the most diversified mammalian families, as it comprises 26 genera and 376 species (Hutterer, 2005). Traditional systematic accounts and recent molecular data suggest that this family is subdivided into two subfamilies, the Soricinae and the Crocidurinae (Dubey et al., 2007d), although the Myosoricinae is sometimes also considered as a distinct subfamily (Hutterer, 2005; Maddalena and Bronner, 1992). Soricine shrews have essen- 
tially a Holarctic distribution with 142 species and 13 genera living in the northern Hemisphere. Crocidurine shrews are restricted to the Old World and represent 209 species from 10 genera, pertaining to the Crocidurini. In addition, 18 species from two genera belong to Myosoricini (Hutterer, 2005). The family Soricidae is believed to have originated in Eurasia, based on the oldest known fossil (20 Myr; Reumer, 1989, 1994), on the high diversity of genera present today on this continent, and according to recent biogeographic reconstructions inferred from extensive molecular data (Dubey et al., 2007d).

Molecular studies based on nuclear and mitochondrial sequences confirmed the monophyly of the tribes and genera within the Soricidae (Dubey et al., 2007d), except for the genus Suncus, which appeared to be paraphyletic. Crocidura shrews were also monophyletic, but only 13 of the 209 current species were analyzed in that previous study. The molecular data suggested several transcontinental exchanges at a higher taxonomic level and complex faunal exchanges of Crocidurinae between Eurasia and Africa (Dubey et al., 2007d). Because few crocidurine shrews were analyzed, and because the focus was on higher taxonomic levels, their biogeographic evolution is still unclear. Indeed, of three proposed scenarios, two argued for a Eurasian origin of Crocidura and one for an African origin (Fig. 3. in Dubey et al., 2007d). Other studies focusing on karyological data of crocidurine shrews (Maddalena and Ruedi, 1994) hypothesized that the genus Crocidura could have evolved in two independent lineages displaying opposite patterns of chromosomal evolution: the first one, endemic to the Afrotropical region, is characterized by species with high chromosome numbers, while the second one, with a Eurasian distribution, is composed of species bearing a presumed ancestral or reduced chromosome number. The only exceptions among Afrotropical species were $C$. luna and $C$. bottegi, both characterized by a plesiomorphic chromosome formula $(2 n=36$ and FN $=56$; see Maddalena and Ruedi, 1994).

Here, we expand the taxon sampling to most of the Old World genera and to approximately 90 species of crocidurine shrews, with particular emphasis on the widespread genus Crocidura. We performed a biogeographic analysis based on a tree resulting from analyses of an alignment of mitochondrial and nuclear genes. The main questions addressed are: (i) Which previous scenarios of biogeographic and karyological evolution are supported by the new molecular reconstructions? (ii) Where is the geographic origin of the crocidurine shrew radiation? (iii) How many faunal exchanges occurred in this group between Africa and Eurasia? (iv) Is there a correlation between this radiation and major geological and/or climatic changes?

\section{Materials and methods}

\subsection{Sampling}

We analyzed a total of 189 samples of Soricidae, that were mostly collected during the course of our previous studies (e.g. Quérouil et al., 2001; Maddalena, 1990a; Ruedi, 1996). In addition, few other samples were obtained from private collections (see Supplementary material 1 ). Specimens were identified by informed specialists, but some African specimens in the genus Crocidura were only provisionally identified, because several species complexes are still in need of thorough taxonomic revisions. Additional taxa with sequences already deposited in GenBank (Dubey et al., 2007d; Ohdachi et al., 2004, 2006; and Quérouil et al., 2001; Ruedi et al., 1998) were also incorporated into the final dataset (see Supplementary material 1 ).

New sequences were deposited in GenBank with the following Accession No. for $c y t-b$, EF524580-EF524796, for 16S, EF524797EF524905, for BRCA1, EF525050-EF525167, and for ApoB,
EF524906-EF525049. The alignment file is deposited in TreeBASE under the submission ID number SN3669.

\subsection{DNA extraction and amplification}

Prior to extraction, most frozen tissue samples were preserved for several years at $-70^{\circ} \mathrm{C}$, then transferred to $80 \%$ ethanol at room temperature. DNA extraction was carried out using the QIA Amp DNA Mini Kit (Qiagen). Double-stranded DNA amplifications of the mitochondrial cytochrome $b$ gene $(c y t-b)$ were performed with the primer pairs L14724/H15149 and C3/H15915 (Irwin et al., 1991; Dubey et al., 2006), and that of the $16 S$ ribosomal sequence (16S) with the primer pair 16sf/16Srbis (Dubey et al., 2007d). Amplification of the breast cancer susceptibility 1 (BRCA1) nuclear gene was performed using the primer pair B1f/B1r (Dubey et al., 2006, 2007d), while the Apolipoprotein $B(A p o B)$ nuclear gene was amplified with the primer pairs $\mathrm{ApoBf} / \mathrm{ApoBr}$ and ApoBf2 $\left(5^{\prime}\right.$ ctg gga aat att aca tat gac $\left.3^{\prime}\right) / \operatorname{ApoBr} 2\left(5^{\prime}\right.$ tca ctg gca ata gtt cc $\left.3^{\prime}\right)$, specifically developed for this study. Amplification conditions for $16 S$ and BRCA1 consisted of 35 thermal cycles (40 for BRCA1) of $60 \mathrm{~s}$ denaturation at $94^{\circ} \mathrm{C}, 60 \mathrm{~s}$ annealing at $55^{\circ} \mathrm{C}$ for $16 \mathrm{~S}$ ( $52{ }^{\circ} \mathrm{C}$ for BRCA1) and $120 \mathrm{~s}$ extension at $72{ }^{\circ} \mathrm{C}$. Amplification conditions for $c y t-b$ consisted of 35 thermal cycles of $30 \mathrm{~s}$ denaturation at $94^{\circ} \mathrm{C}, 45 \mathrm{~s}$ annealing at $50^{\circ} \mathrm{C}$, and 60 s extension at $72{ }^{\circ} \mathrm{C}$. Amplification conditions for the $A p o B$ gene consisted of 40 cycles of $45 \mathrm{~s}$ denaturation at $94{ }^{\circ} \mathrm{C}, 45 \mathrm{~s}$ annealing at $50{ }^{\circ} \mathrm{C}$ and $90 \mathrm{~s}$ extension at $72{ }^{\circ} \mathrm{C}$.

PCR products were visualized on $1 \%$ agarose gels, and purified by centrifugal dialysis using the QIAquick PCR Purification Kit (QIAgen).

Cycle sequencing was performed in a $10 \mu$ total volume containing $1-3 \mu \mathrm{l}$ of amplified DNA, $1 \mu \mathrm{l}$ of $10 \mu \mathrm{M}$ primer and $4 \mu \mathrm{l}$ of ABI PRISM ${ }^{\mathrm{TM}}$ Dye Terminator 1 (Perkin-Elmer). Sequence reactions were run on an ABI 3100 genetic analyser (Applied Biosystems).

\subsection{Phylogenetic analyses}

The coding sequences of $c y t-b$ were aligned by eye, while sequences of $16 S, B R C A 1$, and $A p o B$ were aligned with help of ClustalW (Thompson et al., 1994); the latter alignments were further checked by eye to minimize gaps. Phylogenetic analyses were first performed on the dataset A consisting of 139 taxa with complete sequence data (i.e. all four concatenated genes). Analyses were then performed on a larger dataset $B$ that contained more species (189 taxa), but not all of them were represented by the four genes. The congruence between the four markers was tested on dataset $A$ by performing 100 bootstrap re-samples on each marker with a maximum parsimony (MP) criterion, and comparing the support level thus obtained for each node. Heuristic searches in maximum parsimony (MP; dataset A) analyses were performed using PAUP $* 4.0 \mathrm{~b} 10$ (Swofford, 2001) with 100 random additions of sequences followed by tree bisection-reconnection (TBR) branch swapping, and keeping a maximum of 100 trees during each search. Branch support was estimated using 1000 bootstrap pseudoreplicates using the same heuristic settings. For maximum likelihood analyses (ML), best-fitting models of DNA substitution were selected using hierarchical likelihood ratio tests (hLRTs) implemented in Modeltest 3.06 (Posada and Crandall, 1998). The GTR + I + G model (Rodriguez et al., 1990; Yang, 1996) best fitted both datasets, with an unequal distribution of substitution rates at variable sites (dataset $\mathrm{A}: a=0.343$; dataset $\mathrm{B}: a=0.219$ ) and 6 different substitution types (dataset $A$ : rate $[A-C]=1.5476$, rate $[A-G]=6.6468,[C-T]=17.0424$, rate $[A-T]=1.6272$, rate $[C-$ $G]=0.7895$, rate $[G-T]=1.0000$; dataset $B$ : rate $[A-C]=1.4908$, rate $[A-G]=6.7349,[C-T]=16.8883$, rate $[A-T]=1.5270$, rate $[C-$ $G]=0.7512$, rate $[G-T]=1.0000)$. ML heuristic searches (dataset 


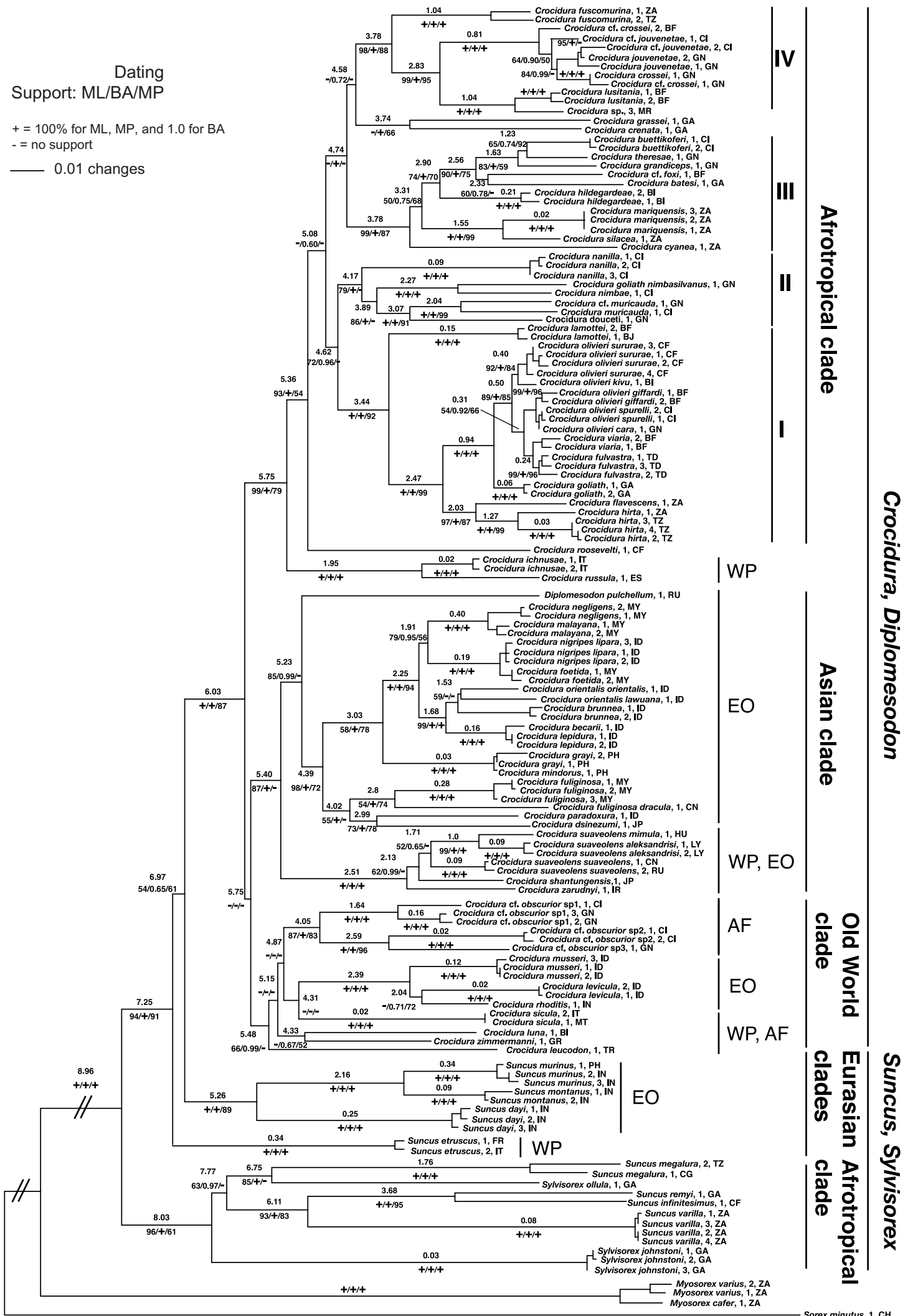

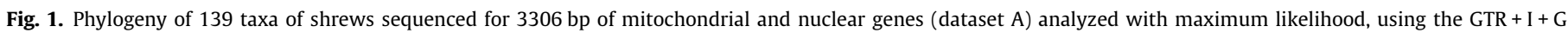
model of substitution. Values above and below the branches are, respectively, molecular dating of nodes and supports for the major branches, for maximum likelihood (ML), bayesian posterior probabilities (BA), and maximum parsimony (MP) analyses (+: support of $100 \%$ for ML and MP, and of 1.0 for BA, -: support <50\% for ML and MP, and <0.5 for BA). The symbol // indicates that the branch length has been shortened. Abbreviations for the distribution of samples are AF for Afrotropical region, WP for West Palaearctic region, and EO for East Palaearctic-Oriental regions. Specimen codes are as in Supplementary material 1. 

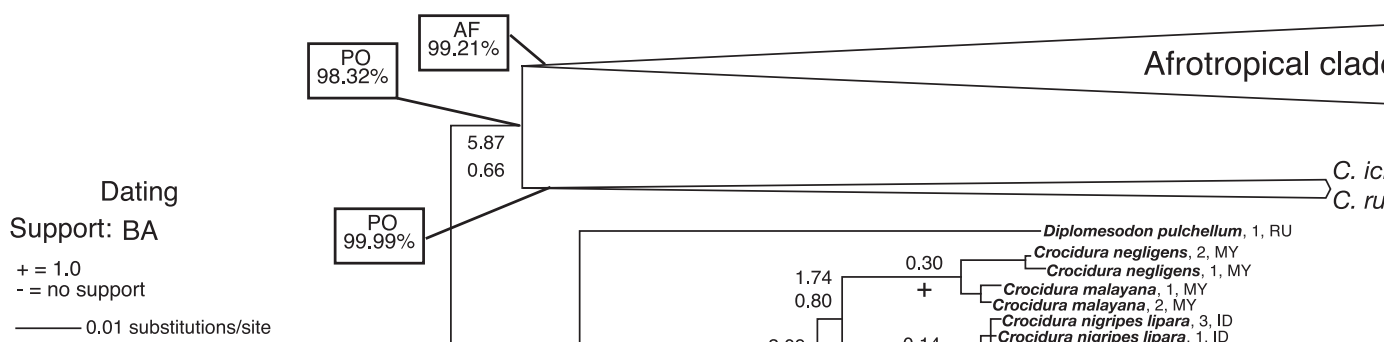

0.01 substitutions/site

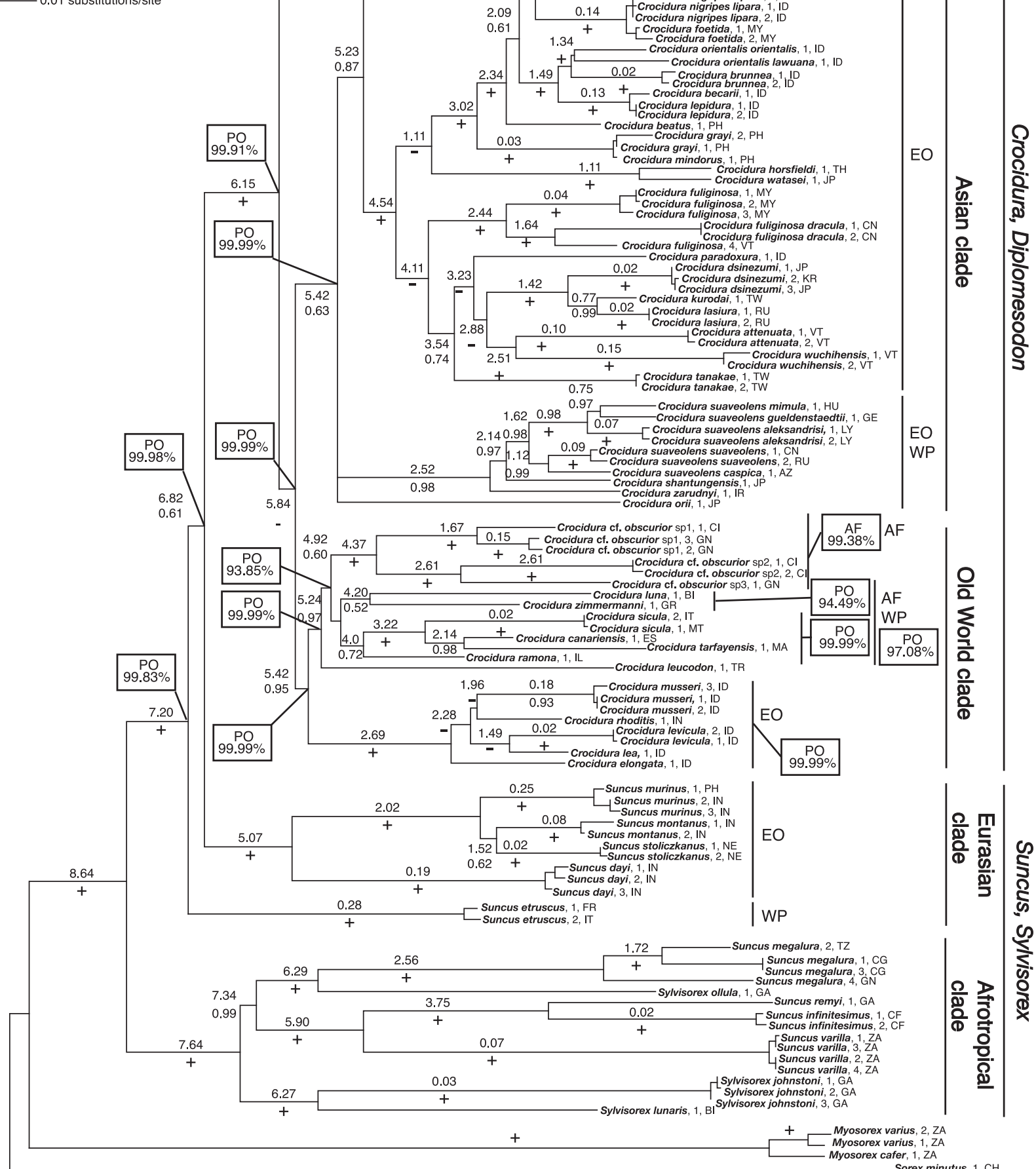

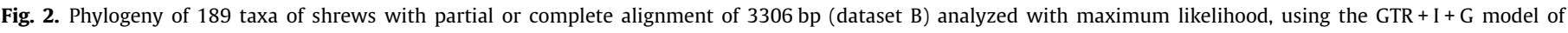

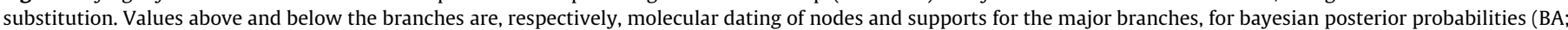

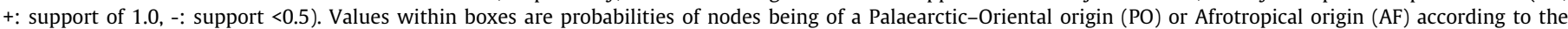

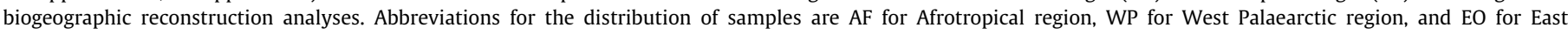
Palaearctic-Oriental regions. Specimen codes are as in Supplementary material 1. 


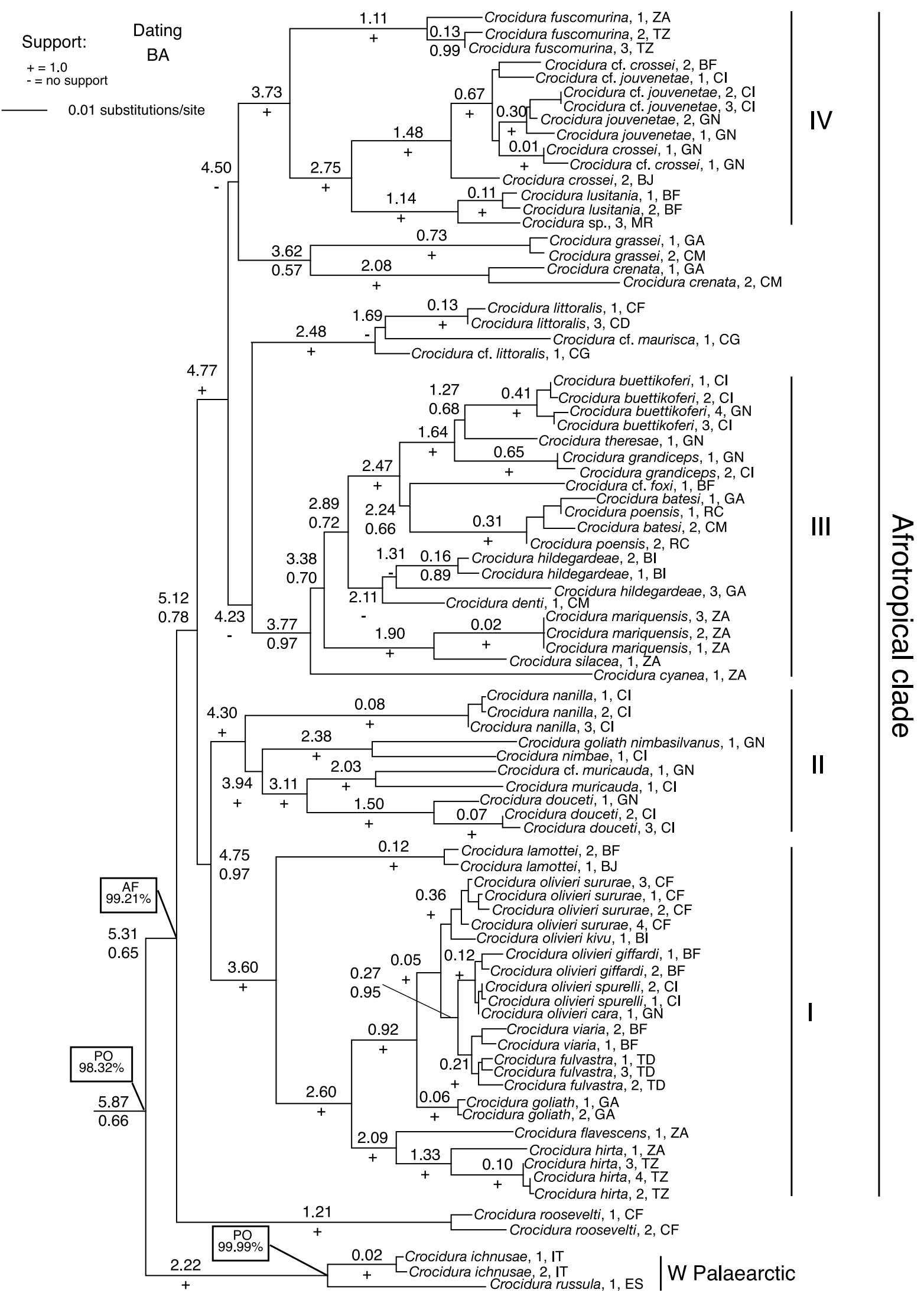

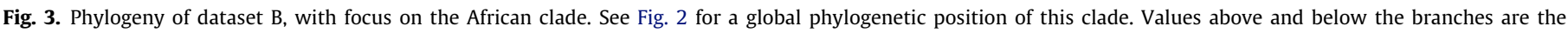

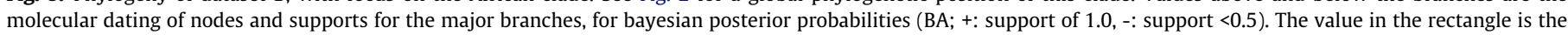
percentage of the node being of an Afrotropical origin (AF) from the biogeographic reconstruction analyses. Specimen codes are as in Supplementary material 1. 
A and B) and bootstrap analyses (1000 replicates; dataset A) were performed with PHYML (Guindon and Gascuel, 2003). Bayesian analyses (BA) were run with MrBayes version 3.1.2.1 (Huelsenbeck et al., 2001) using a GTR + I + G model, and considering a partitioning of the data, corresponding to the four genes, the values of parameters varying between the partitions. Two independent runs were performed, each consisting of four parallel MCMC chains of five million generations (dataset A) and 10 million generations (dataset B), allowing a good convergence of the independent runs. Tree parameters reached stationarity after a burn-in period of two hundred thousand and one million generations (datasets A and B, respectively). Optimal trees were then sampled every 100 generations to obtain the final consensus BA tree and associated posterior probabilities.

\subsection{Molecular dating}

The calibration points used for dating the trees were the oldest known Soricinae-Crocidurinae ancestors (20 Myr, Reumer, 1989, 1994) and the oldest fossil attributed to Crocidura (5.3 Myr, Rzebik-Kowalska, 1998), both originating from Eurasia.

A Bayesian approach was used to estimate absolute divergence time. The ML tree was selected as the best topology for the molecular dating. Each data partition was used separately to estimate the variance-covariance matrix of rates of substitution as implemented in the software Estbranch (Thorne and Kishino, 2002). The four matrices were then used to estimate the divergence time with the program Multidivtime (Thorne and Kishino, 2002). The fossil calibration points were used as a lower bound constraint (minimum age constraint), and the root of the tree was constrained to be at most $50 \mathrm{Myr}$ old. Two independent runs were done to assess convergence. In each run, a one million generation chain was run, with sampling every 100 generations.

\subsection{Reconstruction of biogeographic origin}

To infer the possible biogeographic origin of the Crocidurinae subfamily and of the different genera, we reconstructed ancestral areas of each clade with a maximum likelihood approach using Mesquite 1.05 (Maddison and Maddison, 2004). The current geographic distribution of extant species was coded as 1 for Palaearctic + Oriental (PO) taxa or as 2 for Afrotropical taxa (AF; Supplementary material 1), with the limits between the Palaearctic and Afrotropical regions taken from Corbet (1978). The model of character evolution was a simple stochastic model (Mk1; Lewis, 2001), which assumes a symmetrical and equal rate of change between any two states. The character state frequencies were estimated from the transition probabilities. In this likelihood approach, the probability that a character changes along a branch of the tree is therefore a function of the branch length, with changes being more likely along longer branches than along shorter ones; it also depends on the taxon sampling. We thus based these biogeographic inferences on the ML tree issued from the taxon-rich dataset $\mathrm{B}$. We used the calibrated ML tree obtained by molecular dating (see section above) in order to have branch lengths representing absolute time of divergence.

\section{Results}

\subsection{Phylogenetic relationships}

The most complete dataset (dataset A), i.e. composed of sequences of all four genes for each sample, included 139 taxa with 3560 bp each, of which 254 bp were excluded from the analyses, due to uncertainties in the alignment within the non-coding $16 \mathrm{~S}$ gene. Thus, the final dataset A contained 3306 bp with 1552 vari- able nucleotide positions (ApoB: $851 \mathrm{bp}$; BRCA1: $874 \mathrm{bp} ; 16 S$ : $834 \mathrm{bp} ; \quad c y t-b$ : $747 \mathrm{bp})$, of which 1173 were parsimonyinformative.

The MP bootstrap analyses, performed on each marker, revealed congruent results between the four markers (results not shown). Nevertheless, due to the lower mutation rate of nuclear genes compared to the mitochondrial ones, the topology of terminal branches of $A p o B$ and BRCA1 trees was poorly supported. Inversely, the topology of the basal branches of $16 S$ and $c y t-b$ trees was poorly supported. These differences of resolution resulted in some conflicting topologies between the four markers. However, they were not supported by MP bootstrap values higher than $75 \%$.

All three methods of phylogenetic construction (MP, ML, and $\mathrm{BA}$ ), based on the whole dataset A, were congruent in recovering the same main clades with high support (Fig. 1). Consequently, only the tree obtained by ML is shown here (Fig. 1).

In particular, the two tribes Crocidurini and Myosoricini were each monophyletic with high support (100\% bootstrap, 1.0 posterior probability and $100 \%$ bootstrap for ML, BA, and MP analyses, respectively; the same order of nodal support for the different analyses is reported hereafter). Within the Crocidurini, the genera Suncus and Sylvisorex were polyphyletic, with the African Suncus (S. infinitesimus, S. megalura, S. remyi, and S. varilla) intermingled with species of the genus Sylvisorex (Sy. ollula, Sy. johnstoni). Together, these Afrotropical shrews formed a well-defined clade (96, 1.0, 61; Fig. 1), where Sy. johnstoni was placed in a basal position $(63,0.97,<50)$. This Afrotropical clade was itself an early offshoot of the remaining Crocidurini, with the Eurasian Suncus etruscus being basal to the Asian Suncus (clade S. dayi, S. montanus, S. murinus; 100, 1.0, 89) and the remaining Crocidurini (94, 1.0, 91). In addition, the Asian Suncus were placed further at the base of all representatives of the genus Crocidura (support of Crocidura clade, including Diplomesodon; 100, 1.0, 87).

Within Crocidura, three major clades were strongly supported:

(i) The first clade included all Afrotropical Crocidura (Afrotropical clade, Fig. 1) plus the West Palaearctic pair C. russula/ichnusae $(99,1.0,79)$. The two sister species $C$. ichnusae and $C$. russula were found to be in a basal position $(93,1.0,54)$, followed by the central African $C$. roosevelti, and a succession of four well-supported subclades (I-IV) and a few other single species.

Sub-clade I $(100,1.0,92)$ included the samples of $C$. lamottei, which were basal to the samples of $C$. olivieri from western and central Africa, of $C$. viaria and $C$. fulvastra from northern Africa, $C$. hirta and $C$. flavescens from southern Africa, and the Gabonese samples of C. goliath. Sub-clade II $(79,1.0,<50)$ included west African samples of $C$. nanilla, which were basal to two sister units from west Africa including (i) C. nimbae and C. goliath nimbasilvanus and (ii) C. muricauda, C. cf. muricauda and C. douceti. Sub-clade III $(99,1.0,87)$ included samples of the south African species $C$. cyanea, $C$. silacea, and $C$. mariquensis, and the central African species $C$. hildegardeae, C. batesi, and the western African C. buettikoferi, C. cf. foxi, C. grandiceps, and $C$. theresae. Sub-clade IV $(98,1.0,88)$ included samples of $C$. fuscomurina, which were situated in a basal position to two well-differentiated units, including first the west African taxa of C. cf. crossei, C. cf. jouvenetae, C. crossei, and C. jouvenetae and, second, the samples of $C$. lusitania from Burkina Faso, and one undetermined taxon from Mauritania. The remaining taxa, $C$. grassei and $C$. crenata from central Africa, formed a partially supported unit $(<50$, $1.0,66)$, which clustered with sub-clade IV $(<50,0.72,<50 \%)$.

(ii) The second major clade was essentially formed by Asian representatives of Crocidura and by the monotypic genus Diplomesodon (Asian clade; 87, 0.99, <50; Fig. 1). The Palaearctic samples of $C$. suaveolens, $C$. shantungensis, and $C$. zarudnyi formed a monophyletic unit $(100,1.0,100)$, which was basal to Diplomesodon pulchellum and all other species of the clade $(85,0.97,<50)$. The latter species was the sister taxon to Oriental species $(98,1.0,72)$. The 
continental $C$. fuliginosa samples clustered with the insular $C$. paradoxura from Sumatra and $C$. dsinezumi from Japan $(55,1.0,<50)$. The latter clade was basal to insular SE Asian samples of $C$. grayi and $C$. mindorus from the Philippines, $C$. lepidura and $C$. becarii from Sumatra, $C$. brunnea and $C$. orientalis from Java, $C$. nigripes from Sulawesi, $C$. foetida from Borneo, $C$. negligens from Tioman, and to C. malayana from Peninsular Malaysia.

(iii) The third major clade (Old World clade, 66, 0.99, <50, Fig. 1) was composed of species from all three continents. In particular, it included species from the "Old Sulawesian clade" described in a previous study (Ruedi et al., 1998), a sub-clade consisting of the West African samples $C$. cf. obscurior sp1, sp2, and $\mathrm{sp} 3(87,1.0$, 83 ), the west Palaearctic C. leucodon, $C$. sicula, and C. zimmerman$n i$, and the Afrotropical C. luna, which was sister to C. zimmermanni $(50,0.67,52)$. The precise order of taxa within this clade was not ascertained as none of the basal nodes received strong support in the different phylogenetic reconstructions (Fig. 1). Clade III appears to be the sister clade of the Asian clade, although the support for this relationship is again limited (all $<50$ ).

The dataset B is the same alignment of $3360 \mathrm{bp}$ from four genes, but includes 50 additional taxa (see Supplementary material 1), for which only some of those genes were available. The missing positions were replaced by stretches of Ns and treated as missing data. The taxon sampling of this extended dataset thus consisted of 189 taxa and resulted in 1580 variable positions, of which 1208 were parsimony-informative. The phylogenetic reconstruction based on this expanded taxon sampling (Figs. 2 and 3 ) did not differ significantly from those obtained from the dataset $A$, as all additional species were nested within the clades already defined in the previous analyses.

Within the Crocidurinae, the Afrotropical Suncus and Sylvisorex remain in a basal position to Crocidura (BA support of 1.0; in the following, BA support will be given between brackets), and the additional Suncus megalura, S. infinitesimus, and Sylvisorex lunaris were included within the latter. Within the Eurasian Suncus, S. etruscus remained in a basal position (0.61), and S. stoliczkanus clustered with $S$. montanus (0.62).

Within the clade including Afrotropical Crocidura (0.66), the west Palaearctic $C$. ichnusae and $C$. russula samples remained in a basal position (0.65), followed by $C$. roosevelti $(0.78)$. In addition, the different sub-clades (I-IV) were highly supported $(\geqslant 0.97)$. The new samples of $C$. cf. jouvenetae and C. crossei from West Africa and of the widespread $C$. fuscomurina clustered with their close relative within sub-clade IV. The additional samples of $C$. buettikoferi, C. batesi, $C$. poensis, $C$. hildegardeae, $C$. denti, and C. grandiceps from West or Central Africa were all included within sub-clade III. The samples of $C$. douceti were included within sub-clade II. Finally, the additional samples of $C$. crenata and $C$. grassei clustered with their conspecifics, and the samples of $C$. littoralis, $C$. cf. littoralis, and $C$. cf. maurisca from Central Africa formed a well-supported unit (1.0), distinct to the other sub-clades.

Within the Asian clade, the additional Oriental and East Palaearctic species, $C$. beatus from the Philippines, $C$. horsfieldii from Thailand, C. watasei from Japan, C. lasiura from Russia, C. kurodai and $C$. tanakae from Taiwan, and $C$. attenuata and $C$. wuchihensis from Vietnam clustered with species from the same region (support for this Asian sub-clade: 0.74). The additional samples of C. suaveolens caspica and C. suaveolens gueldenstaedtii clustered with their conspecifics and formed a well-supported clade with C. shantungensis and C. zarudnyi (0.98). The phylogenetic position of the Japanese $C$. orii remained uncertain.

Within the Old World clade, $C$. canariensis from the Canary Islands clustered with $C$. tarfayaensis from Morocco and with $C$. sicula from Sicily (1.0), and C. ramona from Israel was basal to these taxa. The Sulawesian samples $C$. elongata and $C$. lea clustered with the other samples from the same island (1.0). As for dataset A, the basal nodes within this clade were not well-supported.

\subsection{Molecular dating}

Molecular dating based on the two datasets were generally congruent, as there was less than $5 \%$ difference between both estimates. For the sake of simplicity, we report divergence times based on dataset B only, to cover the largest sample of taxa. The split between the clade including the African Sylvisorex and Suncus, and the remaining Crocidurini (Eurasian Suncus, Crocidura, and Diplomesodon) occurred approximately $8.6 \mathrm{Myr}$ ago (95\% CI: 7.6-9.7; Fig. 2). The split between S. etruscus and the other Eurasian Suncus (dayi, montanus, murinus) and the remaining taxa happened $7.2 \mathrm{Myr}$ ago (95\% CI: 6.3-8.1). The split between the Eurasian Suncus and Crocidura (including Diplomesodon) occurred 6.8 Myr ago (95\% CI: 6.0-7.7). Within Crocidura, the split between the Afrotropical clade (including the West Palaearctic C. russula and C. ichnusae) and the other clades occurred 6.2 Myr ago (95\% CI: 5.4-6.9), and the split between the strictly Afrotropical clade and the latter West Palaearctic species occurred 5.9 Myr ago (95\% CI: 5.2-6.6). The split between the Asian and the Old World clades occurred 5.8 Myr ago (95\% CI: 5.1-6.5), whereas the basal nodes of the Afrotropical, Asian, and Old World clades dated, respectively, from 5.3 Myr (95\% CI: 4.6-6.0), 5.4 Myr (95\% CI: 4.7-6.1) and 5.4 Myr (95\% CI: 4.7-6.1).

Within the Afrotropical clade, the splits between the sub-clades I to IV occurred between 5.1 and $4.8 \mathrm{Myr}$ ago (Fig. 3), and the basal nodes of these sub-clades were situated between 4.3 and 3.6 Myr ago. Within the Asian clade, the split between the $C$. suaveolens group and the other Asian taxa occurred $5.4 \mathrm{Myr}$ ago (95\% CI: 4.7-6.1), and the basal node of the $C$. suaveolens group was dated at $2.5 \mathrm{Myr}$ ago (95\% CI: 2.1-3.0). Within this latter group, the split between the northeastern African and European C. s. mimula and $C$. s. gueldenstaedtii occurred $1.0 \mathrm{Myr}$ ago (95\% CI: 0.7-1.2). Within the Old World clade, the split between Palaearctic and Afrotropical taxa occurred between 5.4 (95\% CI: 4.7-6.1) and 4.2 Myr ago (95\% CI: 3.6-4.8).

\subsection{Biogeographic reconstruction}

As the divergence times estimated from dataset A (Fig. 1) and dataset B (Figs. 2 and 3) were similar, only the results based on dataset $B$ were used in the biogeographic reconstructions.

Because the choice of basal taxa in such analyses can strongly influence the biogeographic reconstruction of the focus taxa, we performed successive analyses by deleting each time the most basal taxon (first Myosorex, then Sylvisorex and the Afrotropical Suncus, and finally the Asian Suncus) and compared the results. None of the reconstructions resulting from these successive changes in outgroup resulted in a change in the inferred biogeographic scenarios, nor in the level of ML support of each node.

The common ancestor to all Crocidura and Diplomesodon was most likely of Palaearctic-Oriental origin (ML support of 100\%), as well as the basal node of the Asian and Old World clades (ML support of $100 \%$ ). The common ancestors of these two latter clades were also clearly of Palaearctic-Oriental origin (ML support of 100\%), while the basal node of the Afrotropical clade and the pair of West Palaearctic taxa C. russula and C. ichnusae had a probability of $98 \%$ of being Palaearctic-Oriental (for more details, see Figs. 2 and 3).

\section{Discussion}

\subsection{Current taxonomic and molecular discrepancies}

The African Suncus analyzed here are clearly intermingled within a clade containing all tested Sylvisorex (endemic to Africa), but excluding the Eurasian Suncus (Figs 1 and 2). Two Afrotropical species, Sy. ollula and S. megalura, are clearly sister species and closely 
related on the molecular tree. Indeed, the latter was usually classified into the genus Sylvisorex until Hutterer (2005) proposed to assign it to the genus Suncus based on a closer 16s rRNA genetic distance with the Asian Suncus dayi (Quérouil et al., 2001). This genus assignment is not supported by more comprehensive character and taxon sampling analyses (Figs 1-3), which all show that Eurasian Suncus (i.e. including S. dayi) are clearly distinct from any Afrotropical species assigned either to the genera Suncus (S. megalura, S. remyi, S. infinitesimus, S. varilla) or Sylvisorex (Sy. ollula, Sy.johnstoni, Sy. lunaris). In turn, all these Afrotropical species formed a monophyletic unit in all reconstructions and with very high support (Figs. 1 and 2). Owing to their very close morphological (Butler and Greenwood, 1979; Butler et al., 1989), biochemical (Jenkins et al., 1998) and molecular similarities (Dubey et al., 2007d, and Figs. 1 and 2), all Afrotropical representatives of Suncus should be transferred to the genus Sylvisorex, which would become a monophyletic genus endemic to this biogeographic region.

In turn, all analyzed Eurasian taxa of Suncus, including the typespecies of the genus (Suncus murinus, see Hutterer, 2005), are monophyletic, except for $S$. etruscus, which is apparently more basal to all crocidurine shrews (Figs. 1 and 2). However, the nodal support for the latter placement is weak, and the alternative placement of S. etruscus within the other Eurasian Suncus clade in a basal position remains probable. We thus recommend restricting the genus Suncus to these Palaearctic and Oriental taxa, distinguished morphologically from Crocidura shrews by four pairs of upper unicuspids (total 30 teeth), a plesiomorphic character shared with Sylvisorex (Jenkins et al., 1998).

The genus Crocidura is clearly monophyletic (support for dataset A: $100 \%, 1.0$ and $87 \%$, and for dataset B: 1.0 ) and genetically well distinct from Suncus and Sylvisorex. It differs morpho-anatomically from the latter two genera at least by its dental formula, characterized by the loss of one pair of upper unicuspids (28 teeth), a character considered as derived by Jenkins et al. (1998). The sand-adapted, monospecific genus Diplomesodon, is further distinguished from Crocidura shrews by the reduction of a second pair of upper unicuspids (26 teeth). Molecular reconstructions (Fig. 1) clearly suggest that it is imbedded within Crocidura radiation, with a basal position to the Oriental and Japanese species (support from dataset A: $98 \%, 1.0$, and $72 \%$, for dataset B: 1.0 ). The inclusion of Diplomesodon within the genus Crocidura is also consistent with previous reconstructions based on allozyme data (Maddalena, 1990a,b). Consequently, if taxa have to be strictly monophyletic, then Diplomesodon should be considered as a junior synonym of Crocidura and the binomen Diplomesodon pulchellum should therefore be replaced by Crocidura pulchella. We propose however to follow a less strict definition of the genera (e.g. Brummiti, 2002) and keep this morphologically highly distinctive taxon in its own genus, although this would render Crocidura a paraphyletic taxon.

\subsection{Evolution of karyological versus molecular characters}

According to the present results, Crocidura shrews are split into three major clades. Two of them are represented, respectively, by unique Afrotropical and Palaearctic taxa, and are therefore defined by the common geographic origin of their component taxa. A previous review of karyological data of crocidurine shrews (Maddalena and Ruedi, 1994) also indicated this dichotomy of lineages as most Afrotropical species (including those of the current Afrotropical clade depicted in Figs. 1-3) shared a derived karyotype characterized by increased chromosome number (diploid number $2 n=42-60$ ), while the karyotype of most Palaearctic and Oriental species (including those of the current Asian clade depicted in Figs. $1-3)$ where characterized by less chromosomes $(2 n=22-40$; see references in Maddalena and Ruedi, 1994). The presumed ancestral karyotype $(2 n=36$ and a fundamental number $\mathrm{FN}=54-58)$ was present in the African taxa C. bottegi and C. luna or in the West Palaearctic $C$. canariensis and $C$. tarfayaensis (Vogel et al., 2006). The latter three taxa were also sequenced and analyzed here, and all fell together within the mixed old World clade, the third wellsupported, major clade apparent in molecular reconstructions (Figs. 1-3).

Within the Asian and Afrotropical clades of Crocidura, the karyotype also appears to be a good indicator of phylogenetic relationships. For instance, the widespread Palaearctic taxa of the C. suaveolens group (C. s. suaveolens, C. s. aleksandrisi, C. s. mimula, C. s. gueldenstaedtii, C. shantungensis, and C. zarudnyi, see Dubey et al., 2006, 2007b,c) are characterized by a karyotype of $2 n=40$ and $\mathrm{FN}=50$, and are indeed monophyletic in the molecular reconstructions. Likewise, the monophyly of the African $C$. olivieri group (C. olivieri, C. flavescens, C. fulvastra, C. goliath, C. hirta, and C. viaria; see Dubey et al., 2007a) is well established both by molecular data (Figs. 1-3) and by their unique, shared chromosomal formula of $2 n=50$ and $\mathrm{FN}=66$ or 74 (Maddalena et al., 1987).

The good correspondence between molecular reconstructions and the proposed general framework of karyological evolution in Crocidura shrews bear important phylogenetic information allowing a better understanding of the evolution in this diversified group.

\subsection{Biogeography}

If we assume that the genus Crocidura is composed of four major clades (Afrotropical, West Palaearctic, Asian and Old World), as suggested by the molecular reconstructions (Fig. 1-3), then the most likely origin for the latter three is Palaearctic or Oriental, while the first is Afrotropical. These biogeographic inferences are robust to the choice of the outgroup (Myosorex, Suncus, or Sylviso$r e x)$ and are supported by very high likelihoods ( $>98 \%$ ). We thus envision four possible scenarios of diversification compatible with these biogeographic analyses: the first scenario (Fig. 4A) would be an origin of the genus Crocidura in the Palaearctic-Oriental region and a first basal split before the common ancestor to the Afrotropical clade colonized the African continent. A second transcontinental migration in the same direction would then have occurred, when representatives of the Old World clade colonized secondarily Africa.

Another, less parsimonious scenario (Fig. 4B) would imply an early colonization of the Afrotropical region by the common ancestor to the West Palaearctic and Afrotropical clades, with a subsequent return of a descendant of the common ancestor to the former clade into the West Palaeartic region; then a third transcontinental migration would have occurred from a single lineage of the Old World clade entering Africa secondarily.

A third scenario of the Crocidura radiation originating in the PO region (Fig. 4C) would involve four transcontinental migrations: the same initial two as in scenario $4 \mathrm{~B}$, but then an early colonization of Africa by the descendant of the common ancestor to all the Old World clade, followed by a secondary return of one lineage back into the PO region.

The last envisioned scenario would be compatible with an Afrotropical origin of the Crocidura radiation (Fig. 4D), as proposed by palaeontologists (Butler, 1998; Meester, 1953) or by the higher species diversity found today in this region (McLellan, 1994; Quérouil et al., 2001). This scenario, however, contradicts the current MESQUITE analyses (Figs. 2 and 3), which clearly support a Palaearctic-Oriental origin. Except for the origin of the radiation, this scenario $4 \mathrm{D}$ is identical to $4 \mathrm{~B}$, and would also imply three transcontinental faunal exchanges.

We favor the scenario A to represent the evolution of the Crocidura shrews, because it minimizes the number of transcontinental exchanges and is compatible with the scant fossil record. Accord- 


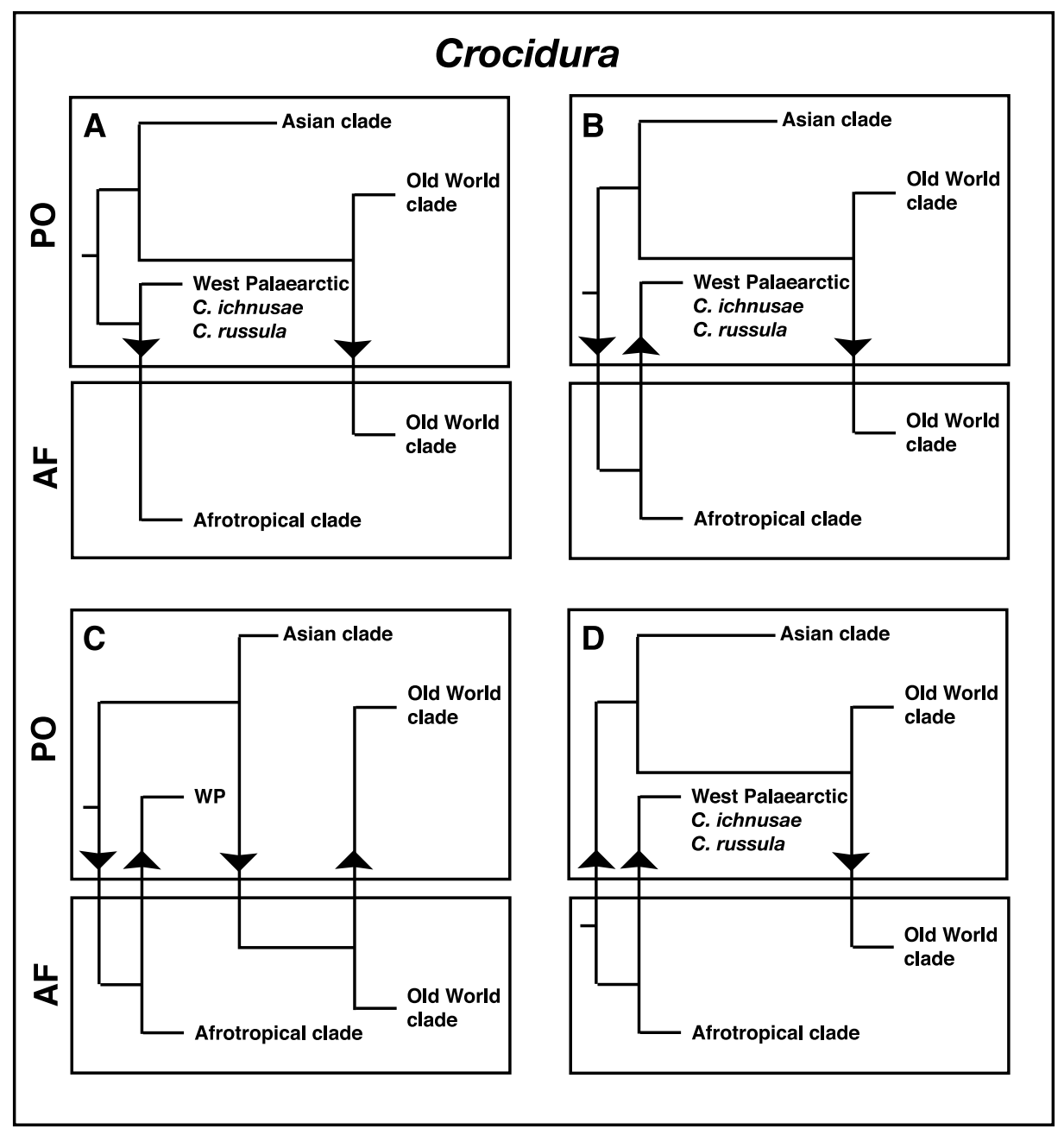

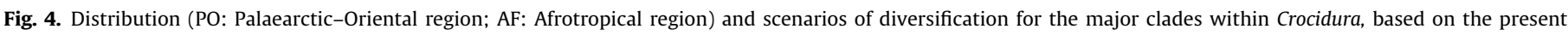
phylogeny (no time scale), considering a Palaearctic-Oriental (A, B and C) or Afrotropical (D) origin of Crocidura.

ing to this scenario A and to the molecular datings, the first event of colonization apparently occurred around $5.9 \mathrm{Myr}$ ago (95\% CI: 5.2-6.6; Figs. 2 and 4) during the Messinian (Upper Miocene). This period is characterized by a salinity crisis (5.3-5.6 Myr ago; Krijgsman et al., 1999) that partially dried out the Mediterranean Sea, which permitted faunal exchanges between Europe and Africa. Thus, it is likely that the first colonizing shrews entered the Afrotropical region via this route at that time, as suggested for several other small mammals (Thomas et al., 1982; Chevret, 1994). This proposed Messinian colonization is reinforced by the clearly basal position of the West Palaearctic C. russula-C. ichnusae compared to the Afrotropical clade. Both species are presently distributed across the western Mediterranean Sea (Brändli et al., 2005; Cosson et al., 2005), which indeed suggests a reminiscence of an ancient colonization through the Gibraltar Strait.

The second event of colonization into Africa from a member of the Old World clade, may have occurred 1 Myr later, at the beginning of the Lower Pliocene (4.9 Myr ago; Fig. 2). This second transcontinental event is more recent, but also coincident with the Messinian salinity crisis, as the confidence interval of the molecular dating fully includes this event (95\% CI: 4.3-5.6).

Within the Afrotropical clade, the splits between the sub-clades (I-IV) occurred apparently within a short time period and shortly after the colonization of Africa by their common ancestor. In fact, the splits are all dated to the Messinian period of the Upper Miocene and the beginning of the Pliocene (5.1-4.8 Myr ago). Similar events occurred within the Asian and Old World clades, where the $C$. suaveolens group and $C$. orii diverged from the other Asian taxa 5.4 Myr ago. A noteworthy fact is the early (about $5.4 \mathrm{Myr}$ ago) differentiation of the endemic species of Sulawesi (C. elongata, C. lea, C. levicula, C. musseri, and C. rhoditis, i.e. the Old Sulawesian clade in Ruedi et al., 1998) from the other Asian, continental taxa, and a subsequent in situ diversification in the Upper Pliocene (2.3 Myr ago).

Consequently, the present species diversity of Crocidura in the Old World results from a relatively long evolution of distinct lineages, which started in the Upper Miocene, as hypothesized by Maddalena (1990a), Butler (1998) and Quérouil et al. (2001), rather than a rapid radiation during the Pleistocene.

The presumed origin of Crocidura shrews, dated to the Upper Miocene (6.8 Myr; 95\% CI: 6.0-7.7) according to our molecular datasets, is slightly older than the age of the first European and Asian fossils found, respectively, in early Pliocene (5 Myr) and Middle Pleistocene deposits (Rzebik-Kowalska, 1998; Storch et al., 1998). Molecular dating of the diversification of Crocidura shrews in Africa (1-5 Myr, Figs. 2 and 3) are also compatible with the age of two different fossils of Crocidura discovered in the Afrotropical region and dating back to the Middle Pliocene. However, the marked morphological differences observed between these two African fossils (Butler, 1998) suggested an older presence of Crocidura on this continent, which is again consistent with the molecular dating. 
Therefore, we highlight a long independent evolution of taxa of different biogeographic affinities, which started in the Upper Miocene for Crocidura. In addition, it reveals a strong influence of the Messinian salinity crisis on transcontinental dispersions and radiations. Our results also show that a large taxon and character sampling is necessary in order to fully understand the phylogenetic relationships in this highly speciose family.

\section{Conclusions}

The phylogenetic relationships between Crocidura shrews appear to be largely consistent with the geographic origin of the species, as well as with their karyological characteristics. Indeed extensive molecular reconstructions clearly highlight that Crocidura shrews are made up of three major clades, two reflecting distinct biogeographic origins (Afrotropical and Asian clades), as suggested by Ruedi et al. (1998), and one including Afrotropical and Asian species (Old World clade) sharing the presumed ancestral karyotype of Crocidura (Vogel et al., 2006).

Previous taxonomic conclusions based on parallel, convergent or plesiomorphic morphological traits, were inappropriate and resulted in the grouping of unrelated taxa, e.g. within the genera Suncus and Sylvisorex (Quérouil et al., 2001). The combination of our new genetic data with previous karyological, paleontological and molecular data was shown to be helpful in resolving the phylogenetic relationships within the subfamily Crocidurinae, as well as its biogeographic origin and radiation.

\section{Acknowledgments}

For providing tissue samples, we acknowledge our colleagues (and the corresponding museum collections): P. Benda, G. Bronner, F.C. Catzeflis, C. Denys (Muséum national d'histoire naturelle, Paris), T. Galewski, L.R. Heaney (The Field Museum, Chicago), R.S. Hoffmann (Smithsonian Institution, National Museum of Natural History, Washington), P.D. Jenkins (Natural History Museum, London), C.D. Lynch, T. Maddalena, E. Paradis, E. A. Rickart (The Field Museum, Chicago) and V. Vohralik. We also thank N. Di Marco for laboratory work and the anonymous reviewers for their helpful comments. This study was supported by the Herbette Foundation, University of Lausanne. The fieldwork was funded by the following programs: Ecofac (http://www.ecofac.org, central Africa), GFA Terra Systems (Guinea), WHO-Ebola R.P. (Ivory Coast), PDRN-NORCADEV (Central African Rep.), W.W.F. (Gabon), PAMF (Benin).

\section{Appendix A. Supplementary data}

Supplementary data associated with this article can be found, in the online version, at doi:10.1016/j.ympev.2008.07.002.

\section{References}

Alroy, J., 2003. Taxonomic inflation and body mass distributions in North American fossil mammals. J. Mammal. 84, 431-443.

Amer, S.A.M., Kumazawa, Y., 2005. Mitochondrial DNA sequences of the AfroArabian spiny-tailed lizards (genus Uromastyx; family Agamidae): phylogenetic analyses and evolution of gene arrangements. Biol. J. Linn. Soc. 85, 247-260.

Azzaroli, A., Guazzone, G., 1979. Terrestrial mammals and land connections in the Mediterranean before and during the Messinian. Palaeogeogr. Palaeocl. 29, $155-167$.

Brändli, L., Handley, L.-J., Vogel, P., Perrin, N., 2005. Evolutionary history of the greater white-toothed shrew (Crocidura russula) inferred from analysis of mtDNA, Y, and X chromosome markers. Mol. Phylogenet. Evol. 37, 832-844.

Butler, P.M., 1998. Fossil history of shrews in Africa. In: Wojcik, J.M., Wolsan, M. (Eds.), Evolution of Shrews. Mammal Research Institute, Polish Academy of Science, Bialowieza, pp. 121-132.

Butler, P.M., Greenwood, M., 1979. Soricidae (Mammalia) from the Early Pleistocene of Olduvaí Gorge. Tanzania. Zool. J. Linn. Soc. 67, 329-379.
Butler, P.M., Thorpe, R.S., Greenwood, M., 1989. Interspecific relations of African crocidurine shrews (Mammalia: Soricidae) based on multivariate analysis of mandibular data. Zool. J. Linn. Soc. 96, 373-412.

Brummiti, R.K., 2002. How to chop up a tree. Taxon 51, 31-41.

Caujapé-Castells, J., Jansen, R.K., 2003. The influence of the Miocene Mediterranean desiccation on the geographical expansion and genetic variation of Androcymbium gramineum (Cav.) McBride (Colchicaceae). Mol. Ecol. 12, 15151525.

Chevret, P., 1994. Etude évolutive des Murinae (rongeurs: mammifères) africains par hybridation ADN/ADN: Comparaison avec les approches morphologiques et paléontologiques, Ph.D. dissertation, University of Montpellier II, Montpellier.

Corbet, G.B., 1978. The Mammals of the Palaearctic Region: A Taxonomic Review. Cornwell University Press, British Museum. (Natural History) pp. 314-315.

Cosson, J.F., Hutterer, R., Libois, R., Sarà, M., Taberlet, P., Vogel, P., 2005. Phylogeographic footprints of the Strait of Gibraltar and Quaternary climatic fluctuations in the western Mediterranean: a case study with the greater white-toothed shrew Crocidura russula (Mammalia: Soricidae). Mol. Ecol. 14, 1151-1162.

De Menocal, P.B., 2004. African climate change and faunal evolution during the Pliocene-Pleistocene. Earth and Planetary Science Letters 220, 3-24.

Drummond, A.J., Ho, S.Y.W., Phillips, M.J., Rambaut, A., 2006. Relaxed Phylogenetics and dating with confidence. PLoS Biol. 4, e88.

Dubey, S., Zaitsev, M., Cosson, J.-F., Abdukadier, A., Vogel, P., 2006. Pliocene and Pleistocene diversification and multiple refugia in a Eurasian shrew (Crocidura suaveolens group). Mol. Phylogenet. Evol. 38, 635-647.

Dubey, S., Antonin, M., Denys, C., Vogel, P., 2007a. Use of phylogeny to resolve the taxonomy of the widespread and highly polymorphic African giant shrews (C. olivieri group, Crocidurinae, Mammalia). Zoology 110, 48-57.

Dubey, S., Cosson, J.-F., Magnanou, E., Vohralík, V., Hutterer, R., Vogel, P., 2007b. Mediterranean populations of the lesser white-toothed shrew (Crocidura suaveolens group): an unexpected puzzle of Pleistocene survivors and prehistoric introductions. Mol. Ecol. 16, 3438-3452.

Dubey, S., Nová, P., Vogel, P., Vohralík, V., 2007c. Cytogenetic and molecular relationships between zarudny's rock shrew, Crocidura zarudnyi (Mammalia: Soricomorpha) and Eurasian taxa. J. Mammal. 88, 706-711.

Dubey, S., Salamin, N., Ohdachi, S.D., Barrière, P., Vogel, P., 2007d. Molecular phylogenetics of Soricidae (Mammalia, Eulipotyphla) reveals timing of transcontinental colonizations. Mol. Phylogenet. Evol. 44, 126-137.

$\mathrm{Fu}$, J., 1998. Toward the phylogeny of the family Lacertidae: implications from mitochondrial DNA 12 S and 16 S gene sequences (Reptilia: Squamata). Mol Phylogenet. Evol. 9, 118-130.

Guindon, S., Gascuel, O., 2003. A simple, fast, and accurate algorithm to estimate large phylogenies by maximum likelihood. Syst. Biol. 52, 692-704.

Harzhauser, M., Piller, W.E., Steininger, F.F., 2002. Circum-Mediterranean OligoMiocene biogeographic evolution-the gastropods' point of view. Palaeogeogr. Palaeocl. 183, 103-133.

Huelsenbeck, J.P., Ronquist, F., Nielsen, R., Bollback, J.P., 2001. Evolution: Bayesian inference of phylogeny and its impact on evolutionary biology. Science 294 2310-2314.

Hutterer, R., 2005. Order Soricomorpha. In: Wilson, D.E., Reeder, D.M. (Eds.) Mammal Species of the World: A Taxonomic and Geographic Reference, third ed. Johns Hopkins University Press, Baltimore, pp. 220-311.

Irwin, D.M., Kocher, T.D., Wilson, A.C., 1991. Evolution of the cytochrome $b$ gene of Mammals. J. Mol. Evol. 32, 128-144.

Jenkins, P.D., Ruedi, M., Catzeflis, F.M., 1998. A biochemical and morphological investigation of Suncus dayi (Dobson, 1888) and discussion of relationships in Suncus Hemprich \& Ehrenberg, 1899, Crocidura Wagler, 1832, and Sylvisorex Thomas, 1904 (Insectivora: Soricidae). Bonn. Zool. Beitr. 47, 257-276.

Krijgsman, W., Hilgen, F.J., Raffi, I., Sierro, F.J., Wilson, D.S., 1999. Chronology, causes and progression of the Messinian salinity crisis. Nature 400, 652-655.

Lewis, P.O., 2001. A likelihood approach to estimating phylogeny from discrete morphological character data. Syst. Biol. 50, 913-925.

Maddalena, T., 1990a. Systématique, Evolution et Biogéographie des Musaraignes Afro-Tropicales et Paléartiques de la Sous-Famille des Crocidurinae: Une Approche Génétique. Ph.D. dissertation, University of Lausanne, Lausanne.

Maddalena, T., 1990b. Systematics and biogeography of Afrotropical and Palaeartic shrews of the genus Crocidura (Insectivora: Soricidae): an electrophoretic approach. Vertebr. Tropics, 297-308.

Maddalena, T., Bronner, G., 1992. Biological systematics of the endemic African genus Myosorex Gray, 1838 (Mammalia: Soricidae). Israel J. Zool. 38, 245-252.

Maddalena, T., Mehmeti, A.M., Bronner, G., Vogel, P., 1987. The Karyotype of Crocidura flavescens (Mammalia: Insectivora) in South-Africa. Z. SäugetierkdInt. J. Mamm. Biol. 52, 129-132.

Maddalena, T., Ruedi, M., 1994. Chromosomal evolution in the genus Crocidura (Soricidae, Insectivora). Special Publication of the Carnegie Museum of Natural History $18,335-344$..

Maddison, W.P., Maddison, D.R., 2004. Mesquite: a modular system for evolutionary analysis. Version 1.06, http://mesquiteproject.org.

McLellan, L.J., 1994. Evolution and phylogenetic affinities of the African species of Crocidura, Suncus and Sylvisorex (Insectivora: Soricidae). In: Merritt, J.F., Kirkland, G.L., Rose, R.K., (Eds.), Advances in the Biology of Shrews, Carnegie Museum of Natural History of Special Publication 18, 379-391..

Meester, J., 1953. The genera of African shrews. Ann. Transvaal. Mus. 22, 205-214

Ohdachi, S.D., Hasegawa, M., Iwasa, M.A., Vogel, P., Oshida, T., Lin, L.-K., Abe, H., 2006. Molecular phylogenetics of soricid shrews (Mammalia) based on mitochondrial cytochrome $b$ gene sequences: with special reference to the Soricinae. J. Zool. 270, 177-191. 
Ohdachi, S.D., Iwasa, M.A., Nesterenko, V.A., Abe, H., Masuda, R., Haberl, W., 2004 Molecular phylogenetics of Crocidura shrews (Insectivora) in east and central Asia. J. Mammal. 85, 396-403.

Posada, D., Crandall, K.A., 1998. MODELTEST: testing the model of DNA substitution Bioinformatics 14, 817-818.

Quérouil, S., Hutterer, R., Barrière, P., Colyn, M., Peterhans, J.C.K., Verheyen, E., 2001 Phylogeny and evolution of African shrews (Mammalia: Soricidae) inferred from 16s rRNA sequences. Mol. Phylogenet. Evol. 20, 185-195.

Reumer, J.W.F., 1989. Speciation and evolution in the Soricidae (Mammalia: Insectivora) in relation with the paleoclimate. Rev. suisse Zool. 96, 81-90.

Reumer, J.W.F., 1994. Phylogeny and distribution of the Crocidosoricinae (Mammalia: Soricidae). In: Merritt, J.F., Kirkland, G.L., Rose, R.K., (Eds.), Advances in the Biology of Shrews, Carnegie Museum of Natural History of Special Publication, 18, 345-356.

Rodriguez, R., Oliver, J.L., Marin, A., Medina, J.R., 1990. The general stochastic mode of nucleotide substitution. J. Theor. Bio. 142, 485-501.

Rogl, F., 1998. Palaeogeographic considerations for Mediterranean and Paratethys seaways (Oligocene to Miocene). Ann. Naturhist. Mus. Wien 99, 279-310.

Ruedi, M., 1996. Phylogenetic evolution and biogeography of Southeast Asian shrews (genus Crocidura: Soricidae). Biol. J. Linnean Soc. 58, 197-219.

Ruedi, M., Auberson, M., Savolainen, V., 1998. Biogeography of Sulawesian shrews: testing for their origin with a parametric bootstrap on molecular data. Mol. Phylogenet. Evol. 9, 567-571.

Rzebik-Kowalska, B., 1998. Fossil history of shrews in Europe. In: Wojcik, J.M. Wolsan, M. (Eds.), Evolution of Shrews. Mammal Research Institute Polish Academy of Science, Bialowieza, pp. 23-92.
Sanderson, M.J., 1997. A non parametric approach to estimating divergence times in the absence of rate constancy. Mol. Biol. Evol. 14, 1218-1231.

Sanderson, M.J., 2002. Estimating absolute rates of molecular evolution and divergence times: a penalized likelihood approach. Mol. Biol. Evol. 19, 101-109.

Storch, G., Qiu, Z.H., Zazhigin, V.S., 1998. Fossil history of shrews in Asia. In: Wojcik, J.M., Wolsan, M. (Eds.), Evolution of Shrews. Mammal Research Institute, Polish Academy of Science, Bialowieza, pp. 93-117.

Swofford, D.L., 2001. PAUP* 4.0: Phylogenetic analyses using Parsimony (*and other methods). Beta version 4.0b10a for PC. Sinauer Associates, Inc., Publishers, Sunderland, Massachusetts.

Thomas, H., Bernor, R., Jaeger, J.J., 1982. Origine du peuplement mammalien en Afrique du Nord durant le Miocène terminal. Geobios 15, 283-397.

Thompson, J.D., Higgins, D.G., Gibson, T.J., 1994. CLUSTAL W: improving the sensitivity of progressive multiple sequence alignment through sequence weighting, position-specific gap penalties and weight matrix choice. Nucleic Acids Res. 22, 4673-4680.

Thorne, J.L., Kishino, H., 2002. Divergence time and evolutionary rate estimation with multilocus data (http://statgen.ncsu.edu/thorne/multidivtime.html). Syst. Biol. 51, 689-702.

Vogel, P., Mehmeti, A.-M., Dubey, S., Vogel-Gerber, C., Koyasu, K., Ribi, M., 2006. Habitat, morphology and karyotype of the Saharan shrew Crocidura tarfayaensis (Mammalia: Soricidae). Act. Theriol. 51, 353362.

Yang, Z., 1996. Phylogenetic analysis using parsimony and likelihood methods. J. Mol. Evol. 42, 294-307. 